\title{
Commercialized Content on Social Media Platforms: Exploring the Drivers of the Viewership of Paid Q\&A
}

\author{
Xueping Yang, xueping.yang @auckland.ac.nz \\ Department of Information Systems and Operations \\ Management, University of Auckland, New Zealand
}

\author{
Hua (Jonathan) Ye, jonathan.ye@uwaterloo.ca \\ School of Accounting and Finance, University of \\ Waterloo, Canada
}

\begin{abstract}
Paying to view others' answers is an emerging business model happening on Weibo, a Chinese version of Twitter. Yet, little is known about what drives people to pay to view others' answers. Based on signaling theory and related literature, we develop a model to predict the viewership of paid-for answers. Using unique panel data of 417 question-to-answers, we find that answer providers' Weibo level, the number of comments that the paid-for answer receives, as well as the question price positively affect the viewership of the paid-for answer. Our findings contribute to the literature and enlighten content providers and platform organization on how to facilitate individual users to commercialize content for profits.
\end{abstract}

\section{Introduction}

Digital technologies and the Internet have liquefied information from its original physical form or device [1]. As a result, information can be easily shared and exchanged at an almost zero marginal cost [2]. Numerous new business models emerge, including Freemium for software and Paywalls for news content [3]. The key to such new business models is information good, that is, products that can be digitized [4].

The main characteristic of an information good is that it is an experience good. It is difficult to detect its actual value before its use [4]. Significant uncertainty and risks exist and prevent consumers from paying for information goods. For example, people may receive a useless or even fraud answer for a concerned question. Thus, it is crucial to know what make consumers pay for such information goods. Past literature suggests multiple ways to price information goods $[5,6]$. Offering quality cues and signals of information goods is one of the most popular ways to attract consumers [7].
Online question \& answer (Q\&A) provides an alternative way for users to acquire and share information [8]. The recently introduced function of paying for answers on some social media platforms has attracted practitioners' attention and interest [9-11]. In December 2016, Weibo.com (one of the largest social media platforms in China) launched the new function of paid Q\&A as a way for users to interact with their followers [12]. In such platforms, those users who provide answers are answer providers, while those users who ask questions and pay for them are question askers. Other users who want to see an answer need to pay RMB 1, the fee of viewership. One viewership is worth RMB 1. From this perspective, the paid-for answer to the question is a type of information good. Following our above discussion, we want to understand what drives users to pay for paid-for answers on social media platforms.

Similar to other types of information goods, the use of quality cues could be important to the consumption of answers- in this case, seen as answer viewership [6]. Unlike what happens with other types of information goods, paying to view answers is not available on other social media platforms. Question askers and answer providers reside in a social network where users have existing relationships. Characteristics, e.g., answer providers' social network statuses, may affect the viewership of answers [13]. Furthermore, the interactions between other users and paid-for answers could also signal the value of answers [14] and potentially affect their viewership. However, previous literature has not studied information goods in the context of social media platforms. Existing theories on information goods have not considered the impacts of social networking and social interactions on the consumption of information goods (answer viewership in our study). Thus, there is a need for investigating what contributes to the viewership of paid-for answers (a unique type of information goods) on social media platforms.

This study aims to address the literature gap by answering this research question: What factors influence the viewership of paid-for answers on social 
media platforms? We will use signaling theory as the theoretical lens to guide our selection of independent variables. As per signaling theory, individuals will search for various signals to decide whether or not to act $[15,16]$. In the context of paid Q\&A on social media platforms, as discussed above, three salient types of signals exist, i.e., (1) signals from question features, (2) signals from answer providers, and (3) signals from social interaction between users and the answer. Based on our literature review and signaling theory, we develop a model that explains how the three types of signals affect the viewership of paid answers.

We collected a unique panel data of 417 paid Q\&As from Weibo Ask for 23 weeks. A total of 9591 observations were used to estimate the model. Panel data help researchers make causal inferences from nonexperimental data. We find that signals from answer providers (e.g., their social media status (level) and the number of followers), signals from question features (i.e., question price), and signals from social interactions (i.e., the number of comments received) significantly affect the viewership of paid-for answers.

The rest of this paper proceeds as follows. First, we review related literature. Then, we hypothesize the relationship between identified factors and answer viewership. Subsequently, the research describes the methodology and data analysis results. Finally, we conclude by discussing the expected contributions and implications for theory and practice.

\section{Theoretical Background}

This section introduces the theoretical foundation of this paper. We first describe the paid Q\&A- Weibo Q\&A. Subsequently, we introduce the dynamics of information goods market. Then, we present the signaling theory as our theoretical lens. We identify various signals that can be used to decide whether to pay to view the answers.

\subsection{Paid Q\&A in Weibo Q\&A}

Our research context is the paid Q\&A in Weibo.com, one of the most popular social media platforms in China. It had 297 million monthly active users and 132 million daily active users in Sept 2016 [17]. Moreover, there are 0.19 million users who were certified celebrities, opinion leaders or specialists in various industries. On average, each certified user had over 0.1 million followers. This platform allows users to post, share and evaluate the content on social networks, such as news, original posts, articles, photos, music, and videos. Consequently, this platform has rich user-generated content. In December 2016, Weibo launched its new service, Weibo Q\&A, supporting mobile device access [9]. Answer providers answer the questions via long texts. Only 500 high-quality users including opinion leaders or specialists in various walks of life were invited first to use this new service of Weibo Q\&A [18]. At the end of July 2017, there were 36,712 users registered as answer providers while only 18,938 had answered one or more questions. Compared to other platforms, Weibo Ask is not only a Q\&A system but also a channel for sharing content.

In paid Q\&A, stakeholders include the platform, question askers, answer providers, and answer viewers. Figure 1 shows the relationship among the three stakeholders. The platform charges $10 \%$ fees of each transactions. Answer providers are those users who register for the Q\&A service. They set the price for their answering service. After the answer provider replies to a question, the question with an inserted link to the paid-for answer will be published on Weibo. People who are interested in the answers need to pay RMB 1 to view the answer, who are called answer viewers. Each viewership receives RMB 1 from an answer viewer. The answer provider and question asker will equally share the viewership revenue. Weibo takes a $10 \%$ commission on all transactions, which is not included in Figure 1.

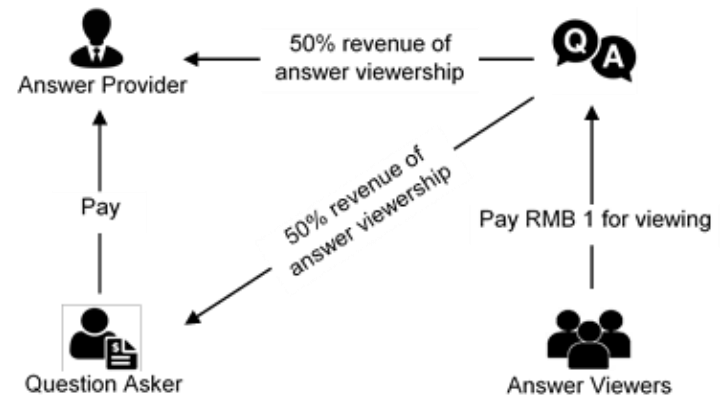

Figure 1. The Business Model of Weibo
Q\&A

The prices set by each answer provider vary. A question asker propose a question to one answer provider with prepayment and will obtain a full refund if the nominated answer provider does not reply within three days. After the answer has been published, the question asker can also profit from the viewership of answer viewers. Charging for viewership expires within three months since the answer provider responses to the question.

The key research question about this business model is what makes other users pay to view answers to others' questions. Past literature on information goods can be useful here to enlighten our study. 


\subsection{Dynamic Information Goods Market}

In a dynamic market for information goods, the commodity can be exchanged indefinitely [19, 20]. Although many indicators, such as a good reputation of the seller or the recognized information quality, would mitigate the information asymmetry problem [21], users' willingness on pay for the information goods can be affected by the following two types of situations.

On one hand, an information good is a type of unique commodity whose value declines over time. This intrinsic nature of diminishing value undermines users' interest in gaining it. Meanwhile, uncertainty caused by information asymmetries can be reduced [21] by increasing environmental cues and information leakage. However, if more positive cues manifest its quality, the willingness to purchase the product might be strengthened. Therefore, time is an important determinant of the value of information goods [20-23].

On the other hand, an information good is experiential. Users can only know its value after they use it [6]. Paying before use is risky. This is especially the case in the context of paid Q\&A. Viewers can only know the content after payment. Before deciding to pay for the viewership, users may need to pick up different cues and signals to decide.

Past literature suggests that individuals use the associated signals to make their decision on information good purchase, and that signaling theory is useful to address information uncertainties [24]. This theory has also been applied to the context of usergenerated content for online reviews [25]. Furthermore, signaling theory is also a useful lens to study information goods [25], and will be used in this study.

\subsection{Signaling Theory}

Signaling theory is useful for describing user behavior when two parties have access to asymmetric information [24, 26]. Information asymmetry exists when individuals or organizations withhold their private information [26]. Asymmetry in information about quality and information about intent will cause moral hazards that result from an individual's using asymmetric information for their own benefits.

Signaling is an important mechanism for reducing information asymmetry [24, 27]. Signalers will send out signals of quality and intent so that the receivers can observe and interpret signals and then react as signalers expect [24]. This theory has been extended to social and economic exchanges and proposes that companies will send out various signals to consumers so that consumers can choose to purchase from them [25]. Thus, substantial research areas have applied it for exploring user choices. For example, Dimoka et al. [16] identified the influence of product uncertainty and seller uncertainty on price premiums in online markets. They found that positive feedback ratings of the seller have a significant effect on price premiums and product uncertainty has a higher effect on price premiums than seller uncertainty.

Past studies have proposed a set of information signals which can attenuate the problem of product uncertainty and information asymmetry between consumers and products [27-29]. Pavlou and Dimoka's research [28] identified several important types of information signals: (1) descriptions of online product (i.e., textual, visual, multimedia) and inherent characteristics of product (i.e., value and usage); (2) certification from third-party (i.e., warranty, ratings); (3) list price of product. In the context of Weibo Ask, similarly, we identify three relevant types of signals: (1) signals from answer providers, including social status on Q\&A platforms (i.e., Weibo level), and social influence (i.e., number of followers) in the platform; (2) signals from users' social interaction with $\mathrm{Q} \& \mathrm{~A}$, such as commenting and sharing Q\&A; (3) signals from question features, such as the question price.

\section{Theoretical model and hypothesis}

Based on past literature and signaling theory, we develop a model shown in Figure 2. We use signaling theory as the overarching theory to derive the general logic. For each construct and relationship, we rely on other related literatures to ground specific arguments.

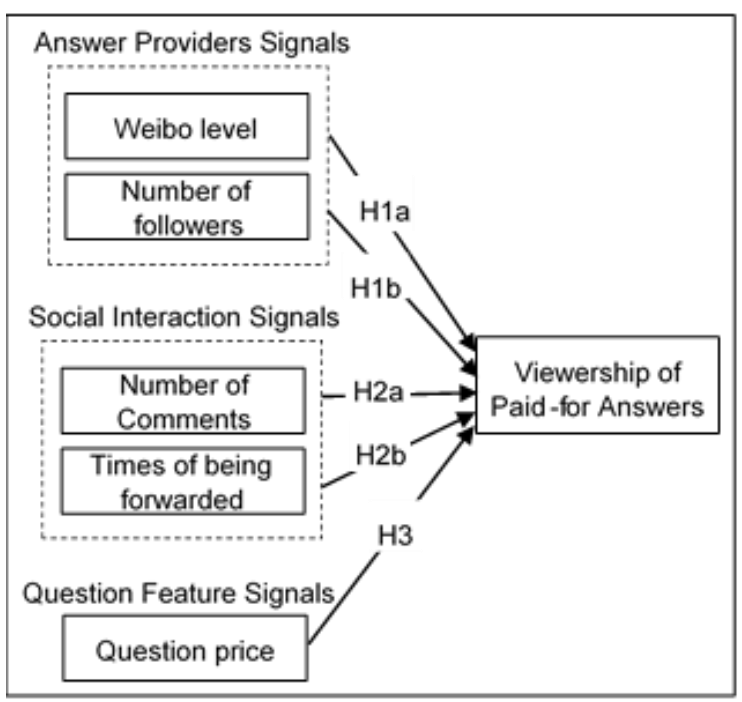

Figure 2. Research Model 


\subsection{Signaling Theory}

Past literature suggests that social media status is an important indicator for users to generate useful content online $[8,30]$. Such status hierarchies can be reflected in levels, tenure, badges that a user has [30]. To achieve the goal of a higher level on such platforms, the user will invest extra efforts in creating high quality content [30]. In other words, users with a higher social media level are more likely to produce original, unique, specialized content.

In the context of product sales, past literature suggests that seller reputation increases the abundance of information [31], and can effectively alleviate information asymmetry between sellers and buyers [21]. Good reputation can affect buyer's perception of the general quality through fulfilling the contractual commitment during the transactions [32]. In the context of social media, Weibo level is an important indicator of answer providers' reputation [8]. Levels can also represent their past contribution and their distinction on such social media platforms [33]. Usually, users with a higher level will not reduce the quality of their contribution to hurt their reputation [34, 35]. In this sense, Weibo level can be a strong quality signal of content generated by the answer providers.

Based on the above reasoning, we can easily argue that an answer provider with a higher Weibo level is more likely to produce high-quality content. Such a quality signal will motivate others to pay for viewing their answers. Thus, we hypothesize

H1a: The level of the answer provider on Weibo positively affects the number of viewership of a paidfor answer.

Another important aspect of social media status is the number of followers [33]. Past literature in knowledge contribution suggests that people tend to be prosocial and contribute quality content to online platforms when the audience size is large [36, 37]. A larger audience size will increase the image and influence power of the contributors. As a result, they will continue contributing high quality content for their targeted audience. Conversely, in the face of a small audience size, individuals believe that their contributions are less likely to be noticed by the public, and will have fewer incentives to improve its quality [37]. This argument is in line with existing literature in social media. Researchers argue that when individuals have more followers, they feel they have more power to influence others $[34,38]$. As a result, they tend to care about their behavior and tend to contribute quality content [34]. As per signaling theory, such quality signals will encourage others to pay to view their answers.

Moreover, past literature on social media has suggested that those who have a large number of followers will have a huge influence on their followers' brand choice and voting behaviors [38, 39]. Borrowing from this logic, answer providers who have a large number of followers will have a huge influence on their followers. Their followers will tend to pay for viewing their answers to express their support and know more about the answer providers. This suggests a positive link between the number of followers and the viewership of answers.

Combining the argument together, we expect that the number of followers that the answer providers have will positively affect the viewership of their answers via the tendency to maintain their social media status and their social influence. Thus, we hypothesize

H1b: The number of followers of the answer provider on Weibo positively affects the number of viewership of a paid-for answer.

\subsection{Signals from Social Interaction}

Signals from social interaction can serve as the third-party certification for the content [28]. Online word-of-mouth is a critical tool to decrease information asymmetry for experienced goods [40, 41]. Past literature suggests that online reviews convey reviewers' evaluation of features and quality of a product and satisfaction or dissatisfaction with their consumption experience [42]. Such product and consumption experience information will significantly reduce product uncertainty and thus improve product sales. Past literature noticed the positive link between online reviews and product sales in various contexts [43]. For example, Chevalier and Mayzlin [44] found the number of reviews has a significant impact on product sales on e-commerce websites.

The underlying mechanism for the relationship is called awareness effect [41]. A large volume of reviews increases public awareness of the object being reviewed [41]. On one hand, a large volume of reviews arouses users' awareness of the existence of such information goods. On the other hand, a large volume of reviews signifies the popularity of such information goods and the hinted quality [45]. As a result, more people will be intrigued to buy such information goods [46]. Similar results have been found in the context of mobile apps [47].

Similarly, the number of comments that a paid-for answer receives represents its popularity and also signifies its innate quality. As per signaling theory, this 
will increase the likelihood of the answer to be viewed by others. Hence, we hypothesize

H2a: The number of comments that the paid-for answer receives positively affects the number of its viewership.

Others' messages being forwarded to one's own network of followers is critical for the transmission of such messages [48]. If a message has been forwarded many times, it indicates that the message will reach to more users' social networking. The probability of more people viewing the answer will increase. As a result, it may receive more viewership. It is similar to the awareness effect that commenting brings.

Furthermore, other users' forwarding represents they are endorsing the message [49]. This will help increase the credibility of such a message. As per signaling theory, credibility signals will improve individuals' likelihood of purchasing such a product [24].

In Weibo, users tend to read postings forwarded by their friends [50]. According to the report of Sina Weibo Data Center (2013), around 90\% Weibo users would like to forward useful, valuable or interesting posts [51]. For the paid-for answers, if the question with a link to the paid-for answer has been forwarded frequently, it will be more likely to notify more people to pay for viewing the answer to the question. Thus, we expect:

$H 2 b:$ The number of times that a paid-for answer has been forwarded on Weibo positively affects the number of its viewership.

\subsection{Price}

Price is always an important indicator of inherent quality studied in various contexts [24, 52]. Past literature on information goods suggests that its value derives from the content [53]. Price indicates the value and the quality. As per signaling theory, this should positively affect the sales of such information goods.

In the context of online Question and Answer, the inherent problem is that questions and answers are free and thus public goods. Their quality cannot be guaranteed. For example, in Yahoo! Answers, there are 823,966 questions and answers generated every day, but only $17.6 \%$ of them were satisfactory [54]. In order to receive high-quality information quickly, users tend to find reliable experts from paid Q\&A systems [55]. Recent studies have shown that financial incentives are helpful in soliciting the user content generation [56]. Financial payment is a way to compensate for their effort and knowledge put in the content $[57,58]$. The amount of financial incentives, i.e., price, could provide a hint about how much effort the answer provider has put into the answer [59] and hence its quality. This suggests that price of the answer to the question should positively affect its viewership. Prior studies on paid answers have identified a positive link between price and answer quality [59, 60]. For example, Haper et al. [60] found that paid answers are judged with higher answer quality. Combining the above argument, we hypothesize

H3: The question price on Weibo $Q \& A$ positively affects the number of viewership of its paid-for answer.

\section{Research Methodology}

\subsection{Research setting}

This study is targeted at paid social Q\&A platform. We select the most noted paid Q\&A platform in China, Weibo Q\&A as our research site. It is based on the largest and most popular Chinese content-sharing platform where the number of monthly active users grew to 411 million in March 2018, and 93\% are represented by mobile users [61].

\subsection{Data Collection}

We employed the keyword search method for obtaining all answered questions which are sorted by latest updated time. Update here refers to the users' interaction activities such as forwarding, giving likes or commenting the Q\&A. The latest interacted Q\&A ranks first. For each Q\&A, the data set includes a web link, price, and numbers of viewership, comments, and reposting of Q\&A, as well as the Weibo level, numbers of followers and postings of the answer provider and question asker. We started data collection on Sep 15, 2017, and obtained unique Q\&A in the following five days, resulting in 493 pieces of unique Q\&A in total and collected data sets every three days until Nov 26, 2017. In total, we have collected 23 times till answer viewership charge expires three months since its release. After removing those which were deleted from the platform during our data collection, 417 pieces of Q\&A remained with a panel dataset of 9591 observations.

\subsection{Control Variables}

We also include control variables that may affect viewers to pay for answers, i.e., answerer followings, asker followings, asker followers and asker postings. 
Answerer followings and asker followings are the numbers of users whom answer providers and question askers follow on Weibo. Asker followers are the number of followers of question askers. Asker postings represent the number of postings of question askers while Answer postings mean the number of postings of answer providers. Descriptive information about all variables is listed in Table 1.

\subsection{Model Specification and Statistical Method}

We tested the hypotheses proposed with a panel regression model. The subscript $i$ in the equation represents the Q\&A and subscript $i$ represents the time.

Viewerships

$=\beta_{1} \log \left(\right.$ Answerer follower $\left.{ }_{i(t-1)}\right)$

$+\beta_{2}$ Weibo_level $_{i(t-1)}+\beta_{3}$ Forwarding $_{i(t-1)}$

$+\beta_{4}$ Comments $_{i(t-1)}+\beta_{5}$ Price $_{i}+$

$+\beta_{6}$ Answerer_postings $s_{i(t-1)}$

$+\beta_{7}$ Asker_followings $s_{i(t-1)}$

$+\beta_{8}$ Asker_followers $i(t-1)$

$+\beta_{9}$ Asker_postings $s_{i(t-1)}+\varepsilon_{i(t-1)}$

where Viewerships $i t$ is the number of the $i^{\text {th }} \mathrm{Q} \& \mathrm{~A}$ viewed at the time $t$; Answerer_follower ${ }_{i(t-1)}$ is the number of followers of the blogger who answered the $i^{\text {th }}$ Q\&A at the time $t-1$; Weibo_level $l_{i(t-1)}$ is the social status of the blogger who answered the $i^{\text {th }} \mathrm{Q} \& \mathrm{~A}$ at the time $t-1$; Answerer_posting $s_{i(t-1)}$ is the number of tweets of the blogger who answered the $i^{t h} \mathrm{Q} \& \mathrm{~A}$ at time $t-1$; Forwarding $_{i(t-1)}$ is the frequency of forwarding the $i^{\text {th }}$ Q\&A at the time $t-1$; Comments Cot $t-1)$ is the number of comments of the $i^{\text {th }} \mathrm{Q} \& \mathrm{~A}$ at the time $t-1$; Price $_{i}$ is the money that the asker pay for the $i^{\text {th }} \mathrm{Q} \& \mathrm{~A}$, which is constant over time. Answerer_followings $s_{i(t-1)}$ is the number of users of the blogger who answered the $i^{\text {th }}$ Q\&A following at the time $t-1$; Asker_followings $s_{i(t-1)}$ is the number of users of the blogger who asked the $i^{t h}$ Q\&A following at the time $t-1 ;$ Asker_followers $_{i(t-1)}$ is the number of fans of the blogger who asked the $i^{t h}$ Q\&A at the time $t-1$; Asker_postings $s_{i(t-1)}$ is the number of tweets of the blogger who asked the $i^{\text {th }} \mathrm{Q} \& \mathrm{~A}$ at time $t-1 ; \varepsilon_{i t}$ is the random error term while $\beta$ is a parameter vector.

Considering the highly skewed of the values for answerer followers, we have performed a natural logtransformation. Apart from the factors we have focused on, some unobservable factors may confound our results. When these factors are stable over (e.g., blogger's effort put in answering questions), fixed or random effects panel data models can be properly employed to account for endogeneity issues [62]. Further, random effects model has a distinct advantage of allowing to include time-invariant factors into regression models. We are interested into the effect of price on the dependent variable, and the price is constant for each Q\&A. Therefore, random effects model is preferred in our study.

\begin{tabular}{|l|c|c|c|c|}
\hline \multicolumn{5}{|c|}{ Table 1. Variable Descriptions } \\
\hline Variables & Mean & SD & Min & Max \\
\hline Viewership & 284.58 & 496.18 & 0 & 5036 \\
\hline Weibo Level & 40.91 & 6.56 & 12 & 48 \\
\hline Ans_followers & 1166128 & 1770421 & 6928 & 11784685 \\
\hline Ans_postings & 23955.91 & 24487.13 & 179 & 96070 \\
\hline Forwarding & 11.00 & 24.99 & 0 & 376 \\
\hline Comments & 14.67 & 31.62 & 0 & 559 \\
\hline Price & 107.59 & 249.08 & 1 & 2198 \\
\hline Ans_followings & 857 & 851 & 31 & 5912 \\
\hline Ask_followings & 336 & 521 & 0 & 6529 \\
\hline Ask_followers & 9941 & 122431 & 0 & 2459823 \\
\hline Ask_postings & 1059 & 3078 & 0 & 35567 \\
\hline
\end{tabular}

\section{Analysis and Results}

We employed the software STATA 15 to perform a random-effects analysis. Descriptive and correlation results of variables are shown in Tables 1 and 2 respectively. To examine the potential multicollinearity problem, we computed variance inflation factors (VIFs). The VIFs for all variables in the analysis ranged from 1.08 to 1.83 , ruling out potential multicollinearity problems [63].

\subsection{Hypotheses Testing}

We estimated a random effects model of viewership of paid-for answers on the main effects of signals from answer providers, social interaction, and question feature with robust standard errors. Results are shown in Table 3. The reason we choose a random effects model instead of a fixed effects model is that we want to test the effects of price which is timeinvariant for each question.

As for signals from answer providers, the Weibo level positively affect the number of viewership $\left(\beta_{2}=\right.$ $2.36, \mathrm{p}<0.01$ ), providing support for H1a. However, the number of followers of answer providers has no significant effect on the viewership, suggesting $\mathrm{H} 1 \mathrm{~b}$ not supported. As for signals from social interaction, 
the number of comments has a positive effect on the indicating that $\mathrm{H} 2 \mathrm{a}$ is supported. However, the number of times that the question has been forwarded has no effect on the viewership, suggesting $\mathrm{H} 2 \mathrm{~b}$ not support. As for the signal from question feature, the price of the viewership of paid answers $\left(\beta_{4}=1.37, \mathrm{p}<0.05\right)$, question has a positive impact on the dependent variable $\left(\beta_{6}=1.18, \quad \mathrm{p}<0.001\right)$, supporting our hypothesis of $\mathrm{H} 3$.

Table 2. Correlations

\begin{tabular}{|l|c|c|c|c|c|c|c|c|c|c|c|}
\hline & 1 & 2 & 3 & 4 & 5 & 6 & 7 & 8 & 9 & 10 & 11 \\
\hline 1.Viewership & 1 & & & & & & & & & & \\
\hline 2.Weibo Level & 0.11 & 1 & & & & & & & & & \\
\hline 3.Ans_followers & 0.10 & 0.55 & 1 & & & & & & & & \\
\hline 4.Ans_postings & -0.04 & 0.49 & 0.57 & 1 & & & & & & & \\
\hline 5.Forwarding & 0.26 & 0.09 & 0.12 & 0.27 & 1 & & & & & & \\
\hline 6.Comments & 0.36 & -0.19 & 0.05 & -0.09 & 0.16 & 1 & & & & & \\
\hline 7.Price & 0.61 & 0.12 & 0.06 & -0.06 & 0.13 & 0.14 & 1 & & & & \\
\hline 8.Ans_followings & -0.18 & 0.23 & 0.12 & 0.29 & 0.00 & -0.13 & -0.13 & 1 & & & \\
\hline 9.Ask_followings & -0.01 & 0.02 & 0.01 & 0.11 & 0.05 & -0.01 & -0.01 & 0.20 & 1 & & \\
\hline 10.Ask_followers & 0.12 & -0.05 & -0.13 & -0.03 & 0.15 & 0.00 & 0.03 & -0.04 & 0.07 & 1 & \\
\hline 11.Ask_postings & 0.10 & 0.04 & 0.08 & 0.06 & 0.04 & 0.03 & 0.15 & -0.02 & 0.24 & 0.28 & 1 \\
\hline
\end{tabular}

\begin{tabular}{|c|c|c|c|}
\hline \multicolumn{4}{|c|}{ Table 3. Data Analysis } \\
\hline \multirow{2}{*}{ IV } & \multicolumn{3}{|c|}{ DV= Viewership } \\
\hline & 1 & 2 & Results \\
\hline Weibo Level & & $2.36^{\star \star}$ & H1a supported \\
\hline $\begin{array}{l}\log \\
\text { isnc fnllniniarcl }\end{array}$ & & 3.05 & H1b not supported \\
\hline Forwarding & & 0.16 & H2a not supported \\
\hline Comments & & $1.37^{\star}$ & H2b supported \\
\hline Price & & $1.18^{\star \star \star}$ & H3 supported \\
\hline Ans_postings & -0.00 & $-0.00^{*}$ & \\
\hline Ans_followings & -0.01 & 0.00 & \\
\hline Ask_followings & -0.00 & -0.00 & \\
\hline Ask_followers & 0.00 & 0.00 & \\
\hline Ask_postings & 0.00 & 0.00 & \\
\hline Fixed Effects & No & No & \\
\hline $\mathrm{R}^{2}$ & 0.03 & 0.42 & \\
\hline $\begin{array}{l}\text { Number of } \\
\text { observations }\end{array}$ & \multicolumn{3}{|r|}{9591} \\
\hline \multicolumn{4}{|c|}{ Significance level: ${ }^{*} p<0.05 ;{ }^{* *} p<0.01 ;{ }^{* * *} p<0.001$} \\
\hline
\end{tabular}

\subsection{Robustness Check}

To test the robustness of our result, we have estimated our data using a fixed effect model with robust standard erros. Results are shown in Table 4. Control variables are not included.

From Table 4, we can see that our results across different methods at large. Price is constant for each question and hence not available in Table 4.

Table 4. Robustness Check

\begin{tabular}{|l|c|}
\hline Independent Variables & DV= Viewership \\
\hline Weibo Level & $1.93^{\star *}$ \\
\hline Log (Ans_followers) & 0.55 \\
\hline Forwarding & 0.15 \\
\hline Comments & $1.34^{*}$ \\
\hline Fixed Effects & Yes \\
\hline$R^{2}$ & 0.15 \\
\hline Number of observations & 9591 \\
\hline Significance level: ${ }^{*} p<0.05 ;{ }^{* *} p<0.01 ;{ }^{* * *} p<0.001$. \\
\hline
\end{tabular}




\section{Discussion and Conclusion}

This study drew upon the signaling theory to examine the impacts of different signals on the viewership of a paid answer. We investigate signals from multiple sources including the answer provider, questions and peer feedback. We then test their impacts with a unique panel dataset.

The present findings show that answer providers' Weibo level, the number of comments that a paid-for answer receives, as well as the question price positively affect the viewership of paid Q\&A. Surprisingly, more followers of an answer provider and Q\&A being forwarded more times do not obviously receive more users' attention.

Our findings have made contributions to existing literature in three significant ways. First, we applied signaling theory to paid Q\&A market for discovering useful information signals. To the best of our knowledge, prior literature attempted to employ this theory in various settings $[24,27]$ but not paid Q\&A systems. This has extended the applicability of signaling theory to an emerging but important context. Second, we have developed a contextspecific framework for paid Q\&A and identifies unique constructs. Our study provides a first attempt to study this phenomenon. This fills our gaps in our understanding about this new phenomenon. Furthermore, our study can pave the way for future research. Third, we have extended past literature in user generated content on social media platforms [37]. Predominant past literature has focused on the voluntary contribution of content on such platforms. We are the first to study paid content on social media platforms, charging others for answering their questions.

Practitioners may also benefit from the results of this study. Content producers can pay more attention to strengthen and improve the signals we discovered in this study when they want to attract more users to pay for the answer. Based on that, the platform organization can also direct their marketing strategy towards these identified and examined attributes. For example, since the level of answerer on Weibo is of great significant effect on information consumption, it is critical to building effective level ranking mechanism.

Future research can study how answer providers price for their answers. It is still unknown what the optimal pricing strategy is for such information goods. Furthermore, since we collected the data from a subset of questions from this platform, it may suffer from self-selection bias. Future research can collect more data from this site and validate whether our findings still hold. In addition, asking a right question may help question askers profit from answer viewership. Future research can study the behavior of question askers using lead user theory [64].

\section{References}

[1] R. F. Lusch and S. Nambisan, "Service innovation: A service-dominant logic perspective," MIS quarterly, vol. 39, no. 1, pp. 155-175, 2015.

[2] R. Normann, Reframing business: When the map changes the landscape. John Wiley \& Sons, 2001.

[3] H. Oh, A. Animesh, and A. Pinsonneault, "Free Versus for-a-Fee: The Impact of a Paywall," Mis Quarterly, vol. 40, no. 1, pp. 31-56, 2016.

[4] C. Shapiro, S. Carl, and H. R. Varian, Information rules: a strategic guide to the network economy. Harvard Business Press, 1998.

[5] S.-y. Wu, L. M. Hitt, P.-y. Chen, and G. Anandalingam, "Customized bundle pricing for information goods: A nonlinear mixed-integer programming approach," Management Science, vol. 54, no. 3, pp. 608-622, 2008.

[6] V. Choudhary, "Use of pricing schemes for differentiating information goods," Information Systems Research, vol. 21, no. 1, pp. 78-92, 2010.

[7] A. Dixit, T. W. Whipple, G. M. Zinkhan, and E. Gailey, "A taxonomy of information technology-enhanced pricing strategies," Journal of Business Research, vol. 61, no. 4, pp. 275-283, 2008.

[8] L. Khansa, X. Ma, D. Liginlal, and S. S. Kim, "Understanding members' active participation in online question-and-answer communities: A theory and empirical analysis," Journal of Management Information Systems, vol. 32, no. 2, pp. 162-203, 2015.

[9] R. Fu. (2017). The rise of paid digital content in China. Available:

https://www.chinainternetwatch.com/19815/paid-digitalcontent-trend-2017/

[10] Technode. (2016). This Chinese Q\&A Platform Is Selling Celebrity Answers For \$750 A Pop. Available: http://technode.com/2016/06/01/fenda/

[11] S. T. K. Jan, C. Wang, Q. Zhang, and G. Wang, "Towards Monetary Incentives in Social Q\&A services," 2017.

[12] E. Yoo. (2017). 4 ways Chinese startups are monetizing their content business. Available: http://technode.com/2017/02/23/china-startups-contentmonetization/ 
[13] A. Susarla, J.-H. Oh, and Y. Tan, "Social networks and the diffusion of user-generated content: Evidence from YouTube," Information Systems Research, vol. 23, no. 1, pp. 23-41, 2012.

[14] P. M. Leonardi, "Social media, knowledge sharing, and innovation: Toward a theory of communication visibility," Information systems research, vol. 25, no. 4, pp. 796-816, 2014.

[15] X. Li and L. M. Hitt, "Self-selection and information role of online product reviews," Information Systems Research, vol. 19, no. 4, pp. 456-474, 2008.

[16] A. Dimoka, Y. Hong, and P. A. Pavlou, "On product uncertainty in online markets: Theory and evidence," MIS quarterly, pp. 395-426, 2012.

[17] B. Fan. (2017). Weibo User Report in 2016. Available: http://data.weibo.com/report/reportDetail?id=346

[18] Y. Zhang. (2016). The slow start of Weibo Q\&A: A "small" Business for Paid Content. Available: http://www.tmtpost.com/2547436.html

[19] M. R. Blouin, "Equilibrium in a decentralized market with adverse selection," Economic Theory, vol. 22, no. 2, pp. 245-262, 2003.

[20] M. Janssen and S. Roy, "On durable goods markets with entry and adverse selection," Canadian Journal of Economics/Revue canadienne d'économique, vol. 37, no. 3, pp. 552-589, 2004.

[21] A. Ghose, "Internet exchanges for used goods: An empirical analysis of trade patterns and adverse selection," Mis Quarterly, pp. 263-291, 2009.

[22] M. C. Janssen and V. A. Karamychev, "Cycles and multiple equilibria in the market for durable lemons," Economic Theory, vol. 20, no. 3, pp. 579-601, 2002.

[23] D. Stolyarov, "Turnover of used durables in a stationary equilibrium: Are older goods traded more?," Journal of Political Economy, vol. 110, no. 6, pp. 13901413, 2002.

[24] B. L. Connelly, S. T. Certo, R. D. Ireland, and C. R. Reutzel, "Signaling theory: A review and assessment," Journal of management, vol. 37, no. 1, pp. 39-67, 2011.

[25] T. Riasanow, H. J. Ye, and S. Goswami, "Generating trust in online consumer reviews through signaling: An experimental study," in System Sciences (HICSS), 2015 48th Hawaii International Conference on, 2015, pp. $3307-$ 3316: IEEE.

[26] M. Spence, "Signaling in retrospect and the informational structure of markets," American Economic Review, vol. 92, no. 3, pp. 434-459, 2002.
[27] A. Kirmani and A. R. Rao, "No pain, no gain: A critical review of the literature on signaling unobservable product quality," Journal of marketing, vol. 64, no. 2, pp. 66-79, 2000.

[28] P. A. Pavlou and A. Dimoka, "Understanding and mitigating product uncertainty in online auction marketplaces," 2008.

[29] A. R. Rao and K. B. Monroe, "The effect of price, brand name, and store name on buyers' perceptions of product quality: An integrative review," Journal of marketing Research, pp. 351-357, 1989.

[30] P. B. Goes, C. Guo, and M. Lin, "Do incentive hierarchies induce user effort? Evidence from an online knowledge exchange," Information Systems Research, vol. 27, no. 3, pp. 497-516, 2016.

[31] A. Ghose, P. Ipeirotis, and A. Sundararajan, "Opinion mining using econometrics: A case study on reputation systems," in Proceedings of the 45th Annual Meeting of the Association of Computational Linguistics, 2007, pp. 416423.

[32] S. Ba and P. A. Pavlou, "Evidence of the effect of trust building technology in electronic markets: Price premiums and buyer behavior," MIS quarterly, pp. 243-268, 2002.

[33] N. Levina and M. Arriaga, "Distinction and status production on user-generated content platforms: Using Bourdieu's theory of cultural production to understand social dynamics in online fields," Information Systems Research, vol. 25, no. 3, pp. 468-488, 2014.

[34] Y. Sun, X. Dong, and S. McIntyre, "Motivation of user-generated content: Social connectedness moderates the effects of monetary rewards," Marketing Science, vol. 36, no. 3, pp. 329-337, 2017.

[35] H. J. Ye, Y. Feng, and B. C. Choi, "Understanding knowledge contribution in online knowledge communities: A model of community support and forum leader support," Electronic Commerce Research and Applications, vol. 14, no. 1, pp. 34-45, 2015.

[36] A. Barasch and J. Berger, "Broadcasting and Narrowcasting: How Audience Size Affects What People Share," Journal of Marketing Research, vol. 51, no. 3, pp. 286-299, 2014.

[37] X. M. Zhang and F. Zhu, "Group size and incentives to contribute: A natural experiment at Chinese Wikipedia," American Economic Review, vol. 101, no. 4, pp. 16011615, 2011.

[38] E. Kim, Y. Sung, and H. Kang, "Brand followers' retweeting behavior on Twitter: How brand relationships influence brand electronic word-of-mouth," Computers in Human Behavior, vol. 37, pp. 18-25, 2014. 
[39] P. T. Metaxas and E. Mustafaraj, "Social media and the elections," Science, vol. 338, no. 6106, pp. 472-473, 2012.

[40] D. Bergemann and J. Välimäki, "Dynamic pricing of new experience goods," Journal of Political Economy, vol. 114, no. 4, pp. 713-743, 2006.

[41] W. Duan, B. Gu, and A. B. Whinston, "Do Online Reviews Matter? An Empirical Investigation of Panel Data," Decision Support Systems, vol. 45, no. 4, pp. 10071016, 2008.

[42] D. Godes and D. Mayzlin, "Using online conversations to study word of mouth communication," Marketing Science vol. 23, no. 4, pp. 545-560, 2004.

[43] H. Ye, C. Chua, and J. Sun, "Enhancing Mobile Data Services Performance via Online Reviews," Information Systems Frontiers, 2017.

[44] J. A. Chevalier and D. Mayzlin, "The Effect of Word of Mouth on Sales: Online Book Reviews," Journal of Marketing Research vol. 43, no. 3, pp. 345-354, 2006.

[45] K. E. Clemons, G. Gao, and L. M. Hitt, "When Online Reviews Meet Hyperdifferentiation: A Study Of The Craft Beer Industry," Journal of Management Information Systems, vol. 23, no. 2, pp. 149-171, 2006.

[46] P. B. Goes, M. lin, and C. A. Yeung, ""Popularity Effect" in User-Generated Content: Evidence from Online Product Reviews," Information Systems Research, vol. 25, no. 2, pp. 222-238, 2014.

[47] H. Ye, C. Chua, and J. Sun, "Enhancing Mobile Data Services Performance via Online Reviews," Information Systems Frontiers, vol. Forthcoming, pp. 1-12, 2017.

[48] A. Malhotra, C. K. Malhotra, and A. See, "How to get your messages retweeted," MIT Sloan Management Review, vol. 53, no. 2, pp. 61-66, 2012.

[49] D. Boyd, S. Golder, and G. Lotan, "Tweet, tweet, retweet: Conversational aspects of retweeting on twitter," in System Sciences (HICSS), 2010 43rd Hawaii International Conference on, 2010, pp. 1-10: IEEE.

[50] W. Guan et al., "Analyzing user behavior of the microblogging website Sina Weibo during hot social events," Physica A: Statistical Mechanics and its Applications, vol. 395, pp. 340-351, 2014.

[51] ChinaInternetWatch. (2014). Sina Weibo Social Network Service Features in 2013. Available: https://www.chinainternetwatch.com/5636/what-weibocan-tell-you-about-chinese-netizens-2013-4/

[52] Z. Gyongyi, G. Koutrika, J. Pedersen, and H. GarciaMolina, "Questioning yahoo! answers," Stanford InfoLab2007.
[53] H. Oh, A. Animesh, and A. Pinsonneault, "Free versus for-a-fee: the impact of a paywall on the pattern and effectiveness of word-of-mouth via social media," MIS Quarterly, vol. 40, no. 1, pp. 31-56, 2016.

[54] H. Shen, G. Liu, H. Wang, and N. Vithlani, "SocialQ\&A: An online social network based question and answer system," IEEE Transactions on Big Data, vol. 3, no. 1, pp. 91-106, 2017.

[55] G. Hsieh, R. E. Kraut, and S. E. Hudson, "Why pay?: exploring how financial incentives are used for question \& answer," in Proceedings of the SIGCHI Conference on Human Factors in Computing Systems, 2010, pp. 305-314: ACM.

[56] G. Burtch, Y. Hong, R. Bapna, and V. Griskevicius, "Stimulating online reviews by combining finanical incentives and social norms," Management Science, vol. 64, no. 5, pp. 2065-2082, 2018.

[57] A. Kankanhalli, H. Ye, and H. H. Teo, "Comparing Potential and Actual Innovators: An Empirical Study of Mobile Data Services Innovation," MIS Quarterly, vol. 39, no. 3, pp. 667-682, 2015.

[58] H. Ye and A. Kankanhalli, "Solvers' participation in crowdsourcing platforms: Examining the impacts of trust, and benefit and cost factors," Journal of Strategic Information Systems, vol. 26, no. 2, pp. 101-117, 2017.

[59] R. D. Ruth, "Conversation as a source of satisfaction and continuance in a question-and-answer site," European Journal of Information Systems, vol. 21, no. 4, pp. 427-437, 2012 .

[60] F. M. Harper, D. Raban, S. Rafaeli, and J. A. Konstan, "Predictors of answer quality in online Q\&A sites," in Proceedings of the SIGCHI Conference on Human Factors in Computing Systems, 2008, pp. 865-874: ACM.

[61] ChinaInternetWatch. (2018). Weibo Performance Overview Q1 2018. Available: https://www.chinainternetwatch.com/24501/weibo-q12018/

[62] J. M. Wooldridge, Econometric analysis of cross section and panel data. MIT press, 2010.

[63] A. Diamantopoulos and J. A. Siguaw, "Formative versus reflective indicators in organizational measure development: A comparison and empirical illustration," British Journal of Management, vol. 17, no. 4, pp. 263-282, 2006.

[64] H. Ye and A. Kankanhalli, "User Service Innovation on Mobile Phone Platforms: Investigating Impacts of Lead Userness, Toolkit Support, and Design Autonomy," MIS Quarterly, vol. 42, no. 1, pp. 165-187, 2018. 